\title{
The Limitations of Bioethics: A Personal History
}

\begin{abstract}
This book has its origins in the work of the first author (SS) as a researcher, teacher, and consultant in the 1980s. During that period, the growing interest in bioethics was coupled with a growing distrust of doctors and the medical profession. To capture that particular historical period and how the first author's views about ethics and health care evolved-in particular, through his own, concrete experience with health professionals of various sorts and in various settings-this chapter is presented in the first person.
\end{abstract}

Keywords Health care - Clinical ethics - Social controls - Codes of ethics - Professional organizations - Ethical confusion - Ethics anxiety Professional education

\section{Social Controls and the Medical Profession}

From 1980 to the end of 1982, I was the associate director of a research project based in Boston and sponsored by the Ethics and Values in Science and Technology (EVIST) program, which was itself funded jointly by the National Endowment for the Humanities and National Science Foundation. That project, "Social Controls and the Medical Profession," was designed to examine the formal (especially, legal) and informal (interpersonal, educational, and social) means by which health professionals (primarily physicians) are controlled - or channeled into doing what we, the public, want them to do. ${ }^{1}$

S. Scher and K. Kozlowska, Rethinking Health Care Ethics, https://doi.org/10.1007/978-981-13-0830-7_2 
At the outset of that project, I considered myself a standard-issue philosopher and lawyer, with a $\mathrm{PhD}$ in moral and political philosophy, a law degree, a year of law practice with a prominent Wall Street law firm, and a semester teaching ethics to undergraduates at New York University. I had done a good deal of reading in bioethics, including the field's leading journal, the Hastings Center Report, and I was well familiar with the newly published, and soon to become leading book in the field, Principles of Biomedical Ethics, by Thomas Beauchamp and James Childress (now in its seventh, 2013 edition).

At that point, and before I had begun to work on the EVIST project, I shared a number of views that were dominant among bioethicistsnamely, that these writings

- were powerful and persuasive efforts to understand ethics in health care;

- could be used to teach health professionals about professional ethics and how they should behave in dealing with their patients; and

- were a necessary means of overcoming the biases and ethical shortcomings of (in particular) a medical profession whose formal ethical code was self-serving, and whose behavior, individually and collectively, was fundamentally mercenary and self-interested.

Looking back, these views seem harsh, but they were actually part of a larger public discourse about American medicine. The bioethics movement developed during exactly the same period as the consumer rights movement in the United States, and the us-against-them stance and perceptions of the consumer rights movement came to be very much a part of the bioethics movement, too. ${ }^{2}$ Thus, along with my bioethicist colleagues, I believed that without the interventions of bioethicists, including philosophers, theologians, lawyers, courts, and legislatures, there was little hope or expectation that the medical profession would or could reform itself.

In his Pulitzer Prize-winning book, The Social Transformation of American Medicine, published in 1982, the sociologist Paul Starr provided a succinct description of the forces at work then. For advocates of patient rights, the

issue was basically professional dominance, and [the advocates'] aim was to increase the power of consumers. This new consciousness about medicine shaped new intellectual developments. In medical ethics, medical 
sociology, and medical history, the dominant sympathies began to change. Much of the traditional work in these fields was written from the physicians' viewpoint, if not by doctors themselves. Increasingly, over the past decade, philosophers, lawyers, sociologists, historians, and feminists, newly interested in health care, have portrayed the medical profession as a dominating, monopolizing, self-interested force. Once a hero, the doctor has now become a villain, and the resentment of this new work by the profession and older scholars in these fields has been intense. (p. 392)

It was against this background-as an educated theoretician with no practical experience in medicine or with doctors and other health professionals - that I began my work on the EVIST project. My education was, of course, about to begin.

The project included regular two-day meetings of roughly a dozen researchers and a dozen doctors. At one of those meetings-well into the second year into the project-someone raised a question about the impact of the bioethics movement on medical practice. In particular, how had the bioethics movement and associated legal cases and new statutory schemes affected the medical treatment that any of the doctors present had given to their patients? The surprising, even flabbergasting response was that none of the doctors present could think of a single instance in which that treatment had actually been different. That is, despite an upheaval in the way that outsiders-bioethicists, consumer activists, courts, and legislatures-perceived doctors and a parallel upheaval in the regulation of medicine, these doctors perceived the actual impact on medical treatment as negligible. The process had changed-for example, informed consent had come to be a legal requirement-but the treatment actually provided to patients had remained essentially constant.

This surprising response dovetailed with some ideas that had occurred to me as I was developing background materials to be distributed in advance of that same meeting. In reading (or, in many instances, rereading) articles from the Hastings Center Report, and in thinking about the approach to medical ethics presented in Principles of Biomedical Ethics, I was struck by the discontinuity between these academic writings and my own perception of how doctors and other health professionals-indeed, anyone except trained philosophers and theologians-actually understood and thought about their ethical responsibilities and about the ethical problems that arose in the course of their work. ${ }^{3}$ 


\section{The Birth of a Pilot Project on Teaching Medical Ethics}

As the EVIST project was coming to an end, I approached the Division of Primary Care at Harvard Medical School about running a pilot project for teaching clinical ethics in the hospital (Cambridge Hospital, in particular). The central features of my proposal were that the primary audience would be medical residents ${ }^{4}$ rather than medical students or medical staff, and that the teaching method would be essentially Socratic; that is, rather than acting like an ethics expert whose primary role was to convey authoritative knowledge, I would primarily ask questions in an effort to bring out, clarify, and build upon the doctors' own thinking.

Although a question arose at this planning stage about considering medical students (on clinical rotations) as the primary audience, my view was that medical students-during their first years in the hospital (until they became residents, after graduation)-were simply too preoccupied with learning the technical $\mathrm{ABCs}$ of medicine to have much energy for the psychosocial side of things. By contrast, medical residents were in their immediately post-medical school years and were consequently, for the first time, actually responsible for the care of patients (though under the supervision of attending physicians). That is, they were faced day-today and hour-to-hour with questions about how to treat patients, how to deal with colleagues, how to address the concerns of families, how to cope with the uncertainties of medical practice, and how to deal with the limits of their capacities, as doctors, to cure patients. For the residents, these questions were incessant, unavoidable, and often difficult, and in addressing the questions, the residents were basically forming the professional selves that would serve as the foundation for all their future work in medicine. In this context the assumption underlying my proposal was that by connecting up ethics concretely with thought, emotion, and action, and by connecting it with the specific concrete problems that the residents wanted and needed to solve, the residents would learn faster and better, and with lasting impact on their work.

As for taking a Socratic approach to teaching-versus a didactic approach that focused on material (in particular, ethical principles) to be learned and then applied-my reasoning was that using the residents' own thinking and feeling (and actions) as the jumping-off point for discussion would make ethics more accessible and tangible for the residents, and more useful to them in their care of individual patients. That is, in pushing residents to analyze their own thinking (about ethics, 
in particular, but also about psychosocial issues, in general), they would come to better understand what they were doing and why, and would also acquire, in the process, the foundation for a lifelong process of reflecting on their work as doctors. ${ }^{5}$

Despite all of the above ideas about what and how to teach the residents, at the outset of the pilot project I still carried around the same prejudices that had come to be entrenched in the bioethics literature and in bioethicists themselves:

- Doctors, like other professionals, had an unswerving commitment to protecting their own self-interests. When push came to shove, self-interest would dominate over the interests of patients.

- To address the above problem of self-interest, doctors needed to be constrained by externally imposed ethical and legal standards. Only then would the interests of patients be protected.

- The traditional code of medical ethics, as opposed to the new bioethics developed by ethics experts outside of medicine, was primarily a self-serving exercise in professional self-protection.

- Ethical problems in medicine were difficult, complex, and capable of being analyzed and solved only through the use of ethical theory and ethical principles.

- It was only persons professionally trained in ethics-namely, philosophers and theologians-who had the expertise required to understand, analyze, and solve such problems.

Everything began to change, and these assumptions-discussed individually below-began to crumble, as soon as I started working in the hospital.

\section{Perceptions and Misperceptions}

\section{Self-Interest}

What impressed me immediately was the degree of dedication and selflessness, rather than self-interest, that the medical residents brought to their work. From the beginning of the day until the end, their goals were to take care of their patients and to learn medicine. The amount of time (in work hours per week) required to achieve these goals was enormous, of course-hence the current, ongoing efforts to establish limits on how 
many hours residents can work a week - but the residents pushed themselves day in and day out to take care of their patients and, in the process, to learn medicine. And if the attending physician, residents, and others had difficulty determining what might be causing particular symptoms, and if the situation was life-threatening or otherwise urgent, the residents might spend long hours in the library trying to sort out the possibilities. It was not that anyone had to ask them to do that; it was simply necessary as the only way of addressing the medical problems of very sick patients.

To "learn medicine" was itself a twofold process. The mass of technical knowledge required to practice medicine is apparent to anyone who has been involved, as either a participant or observer, in the process of medical education. But in addition to the technical aspect of medicine, the medical residents also were developing their sense of themselves as doctors - their professional identities. What was most striking was how difficult it was for the residents to deal with failures of various sorts, with the worst failure being the death of a patient in one's care. Learning to deal with these failures was, in effect, to learn to deal with the limits of medicine, and the limits of one's powers as a doctor, to cure disease and help patients. The distress experienced by the residents in such circumstances is revealing: at the baseline, the residents wanted, more than anything, to help their patients, which made coping with failures so painful and difficult. A large part of my work in hospitals, especially early on as I began to work in each new setting, was devoted to these problems of death and dying, and to helping the residents develop a textured understanding of what they could and could not achieve as doctors.

My experience with, and perceptions of, the senior, attending physicians was somewhat different. All had developed their own professional styles, which ranged from the deeply humanistic and patient-centered doctors, at one extreme, to the dedicated technicians, at the other. Those at the former extreme were regularly more involved with patients and assumed that their open, direct communications with patients would serve to satisfy requirements for informed consent, whereas those at the latter extreme tended, for example, to dot every $i$ and cross every $t$ when it came to informed consent. For them, informed consent was just another technical process that needed to be undertaken, especially to protect them from any potential legal action.

The particular setting that I was working in-hospitals affiliated with Harvard Medical School-was not actually a comfortable environment 
for doctors who preferred to "cut corners" or who were more interested in money than in patients. But the variation in professional styles within that setting brought to mind that the broader field of medicine was not subject to those same institutional constraints, and that the absence of those constraints allowed for a much broader, and unfortunate, range of professional styles and professional goals, such as wealth, power, and dominance. For all my idealism at the time, I realized that I was working in a place that was an example of what was best about American medicine but not therefore representative of it.

\section{Need for Externally Imposed Ethical and Legal Constraints}

Critics' demands for additional ethical and legal constraints on doctors was itself, in large part, a product of seeing them as self-interested professionals whose primary allegiance was to themselves, not their patients. This particular form of reasoning - namely, that more aggressive regulation was urgently needed in order to counteract the endemic self-interest of doctors-rested, I soon came to realize, on a slanted perception of doctors. To be sure, some small percentage of doctors (and other health professionals, too, as in any field of human endeavor) acted primarily, even exclusively, out of self-interest. It was also true, however, that the overwhelming majority of health professionals-whether, for example, residents, attending physicians, nurses, social workers, or psychologists-were dedicated to the task of providing good, appropriate care to patients, and that this task carried with it strong, though implicit, ethical constraints. You can't practice good medicine, for example, without practicing in accordance with the ethical constraints that that are embedded-deeply embedded-in the traditions of medicine. That said, ethical and legal constraints are obviously needed to address problems connected with incompetence, malpractice, and abuses and bad faith of various kinds, including charlatans and doctors who see themselves as dispensing machines for psychoactive drugs.

\section{Traditional Codes of Medical Ethics as Self-Serving and Self-Protective}

Although commentators sometimes dismiss the American Medical Association's Code of Medical Ethics (and virtually all other codes of professional ethics promulgated by professional groups) as largely self-serving and self-protective, I came to realize that this criticism 
doesn't really matter, one way or the other. Even if the claim was correct, it simply wouldn't follow that doctors were therefore less reliable, competent, or trustworthy. Yes, the AMA tries to protect the profession's prerogatives (as in lobbying legislatures and drafting new ethics codes for the medical profession). In the process, the association does try to minimize all unnecessary forms of external intrusions. That's exactly the task of a professional association (for medicine or any other profession) or trade group, and that's why some proportion of the practitioners in any field support such associations. The relevant question, though, is the following: what difference does that make in terms of understanding the work of individual doctors (or other health professionals)? The task at hand is the task at hand, and my own view, which developed through my work with doctors, was that the nominally self-protective activities of groups such as the AMA did not significantly influence how health professionals thought about or approached their work, or the services that they provided to patients. In particular, with important exceptions (such as the need to obtain patients' informed consent), the details of the Code of Medical Ethics are secondary to what, one might say, really counts. During their professional trainingmedical school and the years immediately thereafter-doctors spend countless hours caring for patients, working in teams, and interacting with, and learning from, senior colleagues. The medical profession's Code of Medical Ethics does express important values and give formal recognition to patient autonomy and informed consent. The point, however, is that the impact of such codes is small in comparison to the years of professional training that all doctors-and all health professionals-undergo. And for better or worse, the source of ethical action is in the person, not a formal code.

\section{Ethical Problems in Clinical Medicine Are So Difficult and Complex That Their Resolution Requires Application of Ethical Theory and Ethical Principles}

This claim about the difficulty and complexity of ethical problems in medicine will be discussed, in various forms, throughout the book. What is important to note now is that virtually everything I learned through my experience teaching clinical ethics ran strongly against any such claim. Even in the area of death and dying, with its growing range of unprecedented ethical issues, the questions arising clinically-at the 
bedside-were not about ethical theory but about, say, Mrs. Smith, what her condition was, what she understood about it, and what she wanted (and why). And what about her family? What did they know, and what did they want? Were they prepared, say, for her death, and what did one have to do to help them through what was typically perceived as a family crisis? It would be possible to address such problems in the language of ethical theory (as in determining what rights were at stake), but this type of situation was inescapably, fundamentally human. The language of ethical theory had the effect of distorting and rendering more abstract, rather than clarifying, the problems at hand.

\section{Need for the Ethics Expertise of Philosophers and Theologians}

As might be inferred from the preceding paragraph, there are two ways of approaching and understanding ethical problems in medicine. One way is through theory, and another through practice. After I started to work clinically, I soon realized that doctors, as well as other health professionals, had the capacity to use their own, existing thinking-not just about ethics, but about the personal and social milieu in which medical care is provided-to understand and analyze ethical problems in medicine. By the same token, if I or anyone wanted to help doctors develop their ethical thinking, especially in relation to emerging problems within modern medicine, one would need to build upon that same foundation. Based on my own growing experience in clinical medicine, the need to adopt new or different models of ethical thinking, such as those involving abstract philosophical principles, had yet to be demonstrated.

\section{Two Vignettes}

Separate from the question of how my views about doctors and the medical profession (as described above) came to diverge from those common among bioethicists, however, is the question of whether these different views actually made a difference. Were they merely inconsequential differences in perception between me and other bioethicists, or did the standard assumptions of bioethicists have a tangible, real-world impact on doctors? I soon came to realize that they did. Two examples will illustrate one of the main problems I recognized early on in my clinical work in hospitals. 


\section{Ethical Confusion}

Two years or so after starting to my work in hospitals, I was asked to join an ad hoc conference about the possible use of electroconvulsive therapy (ECT) to treat a chronically depressed patient in his fifties with a life-threatening medical condition. This particular patient had refused ECT many times before, as he was doing again now. During his extensive medical history of problems other than depression, the patient had also refused many of the treatments offered. The patient's physician and psychiatrist-both of whom knew the patient well-believed that he possessed the mental acuity required to make such decisions. A key difference was that, in the past, the patient's medical problems (other than his depression) had been comparatively minor, and he had always, though sometimes only slowly, recovered his health.

The patient had recently been diagnosed with a blocked duct connecting the kidney to the bladder; he had already lost one kidney; and he was refusing the surgery that would correct his present, life-threatening condition. Some of the doctors, nurses, and social workers involved in his care had, at an earlier point, vehemently urged the use of ECT despite the patient's refusal. Since these clinicians had taken the patient's depression to be clouding his judgment, their hope had been that the use of ECT might lift the patient's depression and lead him to accept treatment. And because of the stakes-life or death-even the patient's own doctor and psychiatrist were beginning to second-guess their long-stable judgments about his capacity to make treatment decisions.

Such was the information I had as I prepared for the conference on this emotionally charged case. When the conference began, I asked one of the doctors to discuss how the group of 25 or so caregivers currently perceived the situation. The doctor, only a few years out of medical school, immediately noted that the staff had finally reached a consensus not to use ECT. Speaking with clarity and insight, this young doctor spent about ten minutes explaining the staff's thinking. He described the arduous process of give and take that had ultimately led to a consensus, analyzed the central ethical issues raised by the patient's situation, addressed the psychological issues raised by the case and the staff's conflicting feelings about it, and then drew the implications for the care of the patient.

At the center of the analysis was the view that this particular patient was not simply experiencing a temporary depression that was interfering 
with his thoughts and feelings. Instead, this patient had suffered from depression his entire adult life, and the depression was fully integrated into his adult personality and way of thinking about himself and his life. ${ }^{6}$ Whether the patient was competent or not within the doctrine of informed consent was a matter of continuing disagreement among the staff, but this disagreement, the staff nonetheless agreed, did not matter. What did matter was that administering ECT to this patient would have violated his long-standing preferences, his integrity as a person, his conception of himself, and his long-term efforts to maintain, in the face of chronic and sometimes severe depression, his independence and his control of his life. The staff were therefore prepared to respect the patient's refusal of ECT and to provide whatever supportive care he needed as his kidney function deteriorated and, within a relatively short compass, took his life.

As the doctor was speaking, I realized that his analysis largely overlapped with my own, which left me wondering exactly what I was going to say. But then something astonishing happened. After noting, in summary, that the staff were in agreement on how to proceed and why, the doctor stated that they remained quite at sea concerning the proper ethical analysis of the situation. He closed with the statement, "We don't know what to do." My jaw must have dropped in amazement when I realized that he was not just disparaging, but dismissing, the most impressively acute, lucid analysis of a problem in clinical ethics that I had ever heard given by a doctor (or anyone, for that matter).

That is, at the end of what I considered a remarkable presentation, the doctors and other health professionals present at the conference continued to feel deeply confused and uncertain-despite their having used their own collective wisdom and resources to reach a nuanced, carefully elaborated consensus. What was odd about this continuing uneasiness was that the process of ethical reflection, especially when it reaches a conclusion supported by consensus, typically leads to cognitive and emotional closure. The process itself may be agonizing, but after it is over, people are typically capable of recognizing that they have explored the relevant ethical and emotional issues, given each issue its due weight, and reached a conclusion that reflects a satisfactory integration of all the considerations involved. It is this sense of integration that produces closure, and with it the capacity to cope with and defuse the previous intellectual and emotional turmoil. It is just this sense of integration, of recognizing that they had successfully engaged in a process of ethical reflection, that 
the doctor and his colleagues had not been able to achieve. As I perceived the situation, this continuing state of ethical confusion reflected a baseline lack of confidence in their own ethical capacities.

I understood this state of confusion to be a legacy of the bioethics movement itself. Bioethicists had assumed a public posture as ethics experts and as arbiters of the medical ethic; they had taken on the same role in medical schools and hospitals; they insisted that ethical problems in medicine need to discussed and resolved in terms of abstract ethical concepts and principles, specifically with the tools of modern moral philosophy; and they unequivocally conveyed the impression to doctors that they were mere neophytes in ethics. Could anyone be surprised that doctors had come to question - and distrust - their own ethical judgment?

\section{Ethics Anxiety}

In the preceding case the ethical confusion arose at the end of a process of ethical analysis and reflection. That is, even after reaching a consensus based on an established relationship with the patient, their long familiarity with him and his problems, and an exhaustive analysis of the clinical situation, the clinicians still could not trust their own ethical judgment. The same type of confusion can also arise, as we shall see, at the very beginning of the process of ethical reflection, and where the ethical issues themselves are actually straightforward.

Late on a Friday afternoon, a 62-year-old man was waiting to be discharged from the hospital after a negative evaluation for myocardial infarction. While seated on his bed and discussing his follow-up care with a second-year medical resident, the patient mentioned, without any elaboration, that he was afraid to go home. After the resident asked for an explanation, the patient stated that he was afraid that he would sexually abuse his granddaughter again. He expected that he would have the opportunity to do so within the next two days.

Given the above, it was obvious what had to be done. The medical staff needed to keep the patient in the hospital to protect the granddaughter from another round of sexual abuse. All actions by the resident and other staff needed to be organized, in the short term, toward that end (with the remaining problems to be sorted out later). There was no reason, moreover, to suspect any opposition from the patient, who had, in effect, already asked the hospital for help. 
But that's not what happened.

The resident's immediate response was to ask the patient to wait in his room. The resident then left to consult with the Associate Director of Medicine, who was also Director of Housestaff Education. After the resident notified him of the patient's disclosure, the Associate Director of Medicine decided, as he should have, that the hospital's overriding concern was to protect the granddaughter. He then became intellectually mired, however, in a variety of ethical and legal problems. Did the patient have an ethical or legal right to go home? Did the hospital have an ethical or legal right to force him to stay? Did the hospital have an ethical or legal obligation to inform the victim's parents? Did the hospital have a legal obligation to inform social services or the police?

With no hope or expectation that he could instantly think through this entire set of ethical and legal questions, and with the discharge of the patient imminent, the Associate Director of Medicine proceeded to focus on a single question: did the hospital have a legal right to force the patient to remain in the hospital? The Associate Director then began what proved be a frantic, frustrating, and unsuccessful search for authoritative legal advice. He was unable to reach the hospital's outside legal counsel, in part because it was already late on a Friday afternoon. He was able to reach but unable to obtain any useful assistance, legal or otherwise, from the hospital's social service department or from that of the city in which the hospital was located. The hospital's social service department promised to begin an investigation on Monday (presumably because the social worker in charge had simply assumed that the patient would remain in the hospital over the weekend). After two hours of telephone calls, discussions with several attending physicians and medical residents, and repeated but brief conversations with the nurses responsible for the patient, the Associate Director was left in precisely the same position he had been in when the medical resident originally reported the situation to him.

The Associate Director of Medicine and the rest of the professional staff drawn into the situation were at this point experiencing extreme stress. In the absence of any medical justification for keeping the patient in the hospital, the Associate Director believed that he and the staff were powerless to prevent the patient from being discharged. And if they allowed the patient to go home, they felt that they would be knowing accomplices to another episode of sexual abuse. During this entire 
two-hour period, the patient remained in his room alone and with no knowledge of the medical staff's response to his disclosure.

Forced to act unilaterally, the Associate Director decided that protecting the granddaughter from further abuse was his paramount goal, no matter what the specific ethical or legal rights of the hospital or the patient were. He therefore informed the patient that the medical staff wanted to keep him in the hospital until they could formulate an adequate plan for his return home. The patient accepted this recommendation without any hesitation or objection. On the following Monday, the hospital's department of social services initiated its standard intervention in cases of sexual abuse. The victim's family was notified, and the patient agreed to embark on long-term psychotherapy.

What is ultimately so striking about this case is the contrast between the patient's (predictably) docile acceptance of the Associate Director of Medicine's recommendation, and the medical staff's deepening distress and sense of panic as they attempted to decide upon a course of action. Given the difficulty of admitting to another person that one has engaged in conduct such as sexual abuse, it was apparent from the outset that the patient was himself in extreme distress and wanted to be helped. By contrast, the medical staff seemingly lost their flexibility, perspective, and capacity for problem solving. We see this in the resident's hurried and premature departure from the patient's room, in the continuing inattention to the patient and his almost certain state of growing distress, in the Associate Director of Medicine's exclusive focus on the need for authoritative legal advice, and in the failure of the medical staff to step back and reexamine the clinical situation itself: their own perceptions and reactions to it, the patient's obvious willingness to be helped, and the full range of options open to them. In the end, the situation was resolved effectively only because of the Associate Chief of Medicine, in desperation, decided to disregard the potential or perceived legal risks and to rely on his own, individual ethical judgment concerning what needed to be done. Ironically, the situation would have been resolved quickly and with minimal stress had the Associate Chief of Medicine simply relied on his own clinical skills and his own clinical and ethical judgment in the first place.

Instead, the Associate Chief of Medicine and the other doctors perceived the situation as one requiring ethical and legal expertise-with the former supposedly belonging only to bioethicists, and the latter belonging to lawyers. The result was a deteriorating situation characterized 
by cognitive paralysis, clinical delay, and the potential loss of a patient's good will, without which the situation would have become even more difficult to resolve. In cases like this one, doctors' ethical confusiontheir ethical disorientation-may express itself in a phenomenon that I would later describe as "ethics anxiety" (an intentional parallel to mathematics anxiety $)^{7}$ : when physicians or other health professional are distressed by a situation that they have identified as involving potentially difficult ethical issues, especially a situation that may also involve legal issues, they may become intellectually paralyzed and lose track of their own abilities to analyze the problems, ethical or otherwise, raised by the clinical situation at hand.

\section{Bioethics and Ethical Self-Doubt}

Underlying both the ethical confusion in our first vignette and the phenomenon of ethics anxiety in our second is the radical discontinuity between the ethical and legal standards of bioethics and the concrete, clinically oriented ethical thinking of doctors and other health professionals. And in both cases, this discontinuity created enormous stress and left the physicians unable to act in accordance with their own clinical training and ethical and professional judgment. Indeed, the physicians and other health professionals did not trust themselves, thereby compromising their efforts to proceed with direct, timely, and effective responses to the clinical situations they encountered.

More broadly, what these two cases suggest is that the bioethics movement, rather than assisting doctors and other health professionals to address ethical issues as they arise clinically, has actually undercut, in some respects, their capacities to make such judgments. This realization dovetailed with my growing skepticism, as discussed earlier, concerning the standard assumptions then current in bioethics-about doctors, the need to control their behavior (and misbehavior) through new ethical and legal standards, the role of the organized medical profession, the nature of ethical problems in medicine, and the need for ethics expertise. All my experience suggested that the way to improve and maintain ethical thought and conduct in medicine and other fields of health care was by building on health professionals' existing resources-how they think, feel, and act-rather than by trying to achieve those same goals by imposing a way of thinking that simply doesn't come naturally. 


\section{The More Things Change, the More They Remain the Same}

Now, let's fast-forward two decades, when I happened to come across a prestigious medical journal's special issue on clinical ethics. Much to my distress and surprise, I found that little had changed from when I had taught clinical medical ethics in Harvard Medical School hospitals twenty years before. The articles were almost exclusively oriented toward theoretical, principle-based analyses of clinical situations, mostly extremely difficult ones; if read by practicing physicians, some of the articles might have been admired as intellectually impressive even though they might nevertheless have fallen short, even far short, of clinical relevance. My own response to the articles was that they failed to connect up with the clinical milieu or with the actual concerns of doctors and other health professionals. What I immediately realized was that the bioethical assumptions and the abstract mode of argumentation that I had put behind myself so many years before were continuing to dominate the field of bioethics, to the disadvantage of the field itself, practicing physicians, other health professionals, and, most importantly, their patients. And it was then that I decided that it was time for me to do some more writing and to do what I could to free the clinician's voice, which had been silenced far too long. I published several articles on bioethics shortly thereafter (Scher 2010; Scher and Kozlowska 2011, 2012), and not long after that decided to write this book-and in tandem with a clinician, to ensure that the book never loses its clinical focus and relevance.

That said, the approach presented here is not specifically based on the assumption that the bioethics movement has helped or not helped doctors and other health professionals address ethical issues that arise in their clinical work. The fundamental claim, instead-both for me and my coauthor-is that, from the perspective of learning to think and act ethically within health care settings, there's simply a better, more useful way of understanding health care ethics and the demands it places on clinicians. In particular, the beginning of wisdom is to see clinical ethics, like all ethics, as embedded within the self and as deeply interconnected with each person's thinking, feeling, and acting. To ignore this concrete human foundation is to undercut, at the outset, the possibility of understanding and advancing clinical ethics. 


\section{Notes}

1. Formal social controls are externally imposed and coercive, often involve the law, and include such things as licensing (e.g., to practice medicine), official recognition of expertise (as in board certification in a specialty), mandated legal requirements (e.g., informed consent), and legal actions (e.g., to obtain recovery for injuries from malpractice). Informal social controls are the interpersonal processes intended to bring persons noncoercively to adopt certain values and to behave, preferably from within, in particular ways. For our purposes in this book, the most common forms of informal social control are (other than professional ethics as such) professional education and socialization, the process by which health professionals learn what they need to know and to do in order to become professionally competent.

2. This theme is taken up again in Chapter 3.

3. Over the years, as I worked with doctors and other health professionals, I became more and more convinced that, if you wanted to help health professionals develop their own ethical thinking-to become "more ethical"you needed to start at the baseline of their own present ethical thinking rather than expecting them to engage in the unnatural, cumbersome process of applying abstract ethical principles to the concrete world of clinical health care. But at the particular time that I'm writing about in this paragraph, these ideas had yet to coalesce.

4. The terminology for referring to doctors who have just finished medical school but who are, as is generally required, undergoing further, postgraduate training differs from country to country. For ease of exposition, we will be using the standard U.S. term resident to refer to doctors during that training period, which itself precedes a possible further period of specialist training as fellows. As an example of the latter, a doctor who has completed a residency in medicine (three years) might further specialize by doing a fellowship in oncology or cardiology.

5. Of note, the broader audience for this pilot project included the full range of health professionals working in the hospital: attending physicians, medical students, nurses, psychologists, social workers, and even (to the extent that 1 encountered them) hospital administrators. Moreover, I soon came to see that these disparate groups all encountered, and analyzed, ethical problems as thoughtful human beings who only happened to be doctors or nurses or social workers. To make any fundamental distinction among these groups of caregivers was to miss their fundamental sameness.

6. This sort of integration is the focus of David Shapiro's classic study, Neurotic Styles (1965).

7. For a fuller discussion of this case, see Stephen Scher, "Ethics Anxiety" (2010). 


\section{REFERENCES}

Beauchamp, T. L., \& Childress, J. F. (1979). Principles of biomedical ethics. New York: Oxford University Press.

Beauchamp, T. L., \& Childress, J. F. (2013). Principles of biomedical ethics (7th ed.). New York: Oxford University Press.

Scher, S. (2010). Ethics anxiety. Australian and New Zealand Journal of Family Therapy, 31(1), 35-42.

Scher, S., \& Kozlowska, K. (2011). The clinician's voice and the limits of bioethics. Australian and New Zealand Journal of Family Therapy, 32(1), 15-32.

Scher, S., \& Kozlowska, K. (2012). Thinking, doing, and the ethics of family therapy. American Journal of Family Therapy, 40(2), 97-114.

Shapiro, D. (1965). Neurotic styles. New York: Basic Books.

Starr, P. (1982). The social transformation of American medicine. New York: Basic Books.

Open Access This chapter is licensed under the terms of the Creative Commons Attribution-NonCommercial-NoDerivatives 4.0 International License (http:// creativecommons.org/licenses/by-nc-nd/4.0/), which permits any noncommercial use, sharing, distribution and reproduction in any medium or format, as long as you give appropriate credit to the original author(s) and the source, provide a link to the Creative Commons license and indicate if you modified the licensed material. You do not have permission under this license to share adapted material derived from this chapter or parts of it.

The images or other third party material in this chapter are included in the chapter's Creative Commons license, unless indicated otherwise in a credit line to the material. If material is not included in the chapter's Creative Commons license and your intended use is not permitted by statutory regulation or exceeds the permitted use, you will need to obtain permission directly from the copyright holder.

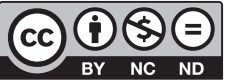

